\title{
Women's attitudes and beliefs towards specific contraceptive methods in Bangladesh and Kenya
}

Kazuyo Machiyama ${ }^{1 *}$ (D), Fauzia Akhter Huda², Faisal Ahmmed², George Odwe' ${ }^{3}$. Francis Obare ${ }^{3}$, Joyce N. Mumah", Marylene Wamukoya ${ }^{4}$, John B. Casterline ${ }^{5}$ and John Cleland ${ }^{1}$

\begin{abstract}
Background: Missing from the huge literature on women's attitudes and beliefs concerning specific contraceptive methods is any detailed quantitative documentation for all major methods in low- and middle-income countries. The objectives are to provide such a documentation for women living in Matlab (rural Bangladesh), Nairobi slums and Homa Bay (rural Kenya) and to compare the opinions and beliefs of current, past and never users towards the three most commonly used methods (oral contraceptives, injectables and implants).

Methods: In each site, 2424 to 2812 married women aged 15-39 years were interviewed on reproduction, fertility preferences, contraceptive knowledge and use, attitudes and beliefs towards family planning in general and specific methods. We analysed the data from round one of the prospective cohort study.

Results: While current users typically expressed satisfaction and held more positive beliefs about their method than past or never users, nevertheless appreciable minorities of current users thought the method might pose serious damage to health, might impair fertility and was unsafe for prolonged use without taking a break. Larger proportions, typically between $25 \%$ and $50 \%$, associated their method with unpleasant side effects. Past users of pills and injectables outnumbered current users and their beliefs were similar to those of never users. In all three sites, about half of past injectable users reported satisfaction with the method and the satisfaction of past implant users was lower.

Conclusions: High levels of contraceptive use can clearly co-exist with widespread misgivings about methods, even those that are widely used. Serious concerns about damage to health, long term fertility impairment, and dangers of prolonged use without taking a break were particularly common in the Kenyan sites and these beliefs may explain the high levels of discontinuation observed in Kenya and elsewhere in Africa. This documentation of beliefs provides useful guidance for counselling and informational campaigns. The generally negative views of past users imply that programmes may need not only to improve individual counselling but also strengthen community information campaign to change the overall climate of opinion which may have been influenced by dissatisfaction among past users.
\end{abstract}

Keywords: Contraception, Contraceptive methods, Attitude, Belief, Satisfaction, Kenya, Bangladesh

\footnotetext{
* Correspondence: Kazuyo.Machiyama@lshtm.ac.uk

${ }^{1}$ Faculty of Epidemiology and Population Health, London School of Hygiene

and Tropical Medicine, Keppel Street, London WC1E 7HT, UK

Full list of author information is available at the end of the article
}

C The Author(s). 2018 Open Access This article is distributed under the terms of the Creative Commons Attribution 4.0 International License (http://creativecommons.org/licenses/by/4.0/), which permits unrestricted use, distribution, and reproduction in any medium, provided you give appropriate credit to the original author(s) and the source, provide a link to the Creative Commons license, and indicate if changes were made. The Creative Commons Public Domain Dedication waiver (http://creativecommons.org/publicdomain/zero/1.0/) applies to the data made available in this article, unless otherwise stated. 


\section{Plain english summary}

In low- and middle-income countries, women's beliefs about specific contraceptive methods are not well understood. This study documents the beliefs about eight contraceptive methods among women living in Matlab (rural Bangladesh), Nairobi slums and Homa-Bay (rural Kenya) and compares the opinions of current, past and never users of the most commonly used methods (oral contraceptives, injectables and implants). In each site, we interviewed 2424 to 2812 married women aged 1539 years. As expected, we found that current contraceptive users were typically satisfied and had more positive beliefs about their method than past or never users. Nevertheless, large minorities of current users thought that their method might cause serious health problems, impair future childbearing and was unsafe to use for a long time; higher proportions $(25-50 \%)$ reported that their method use caused unpleasant side effects. Past users of pills and injectables outnumbered current users and their beliefs were similar to never users. In all three sites, about half of past injectable users reported satisfaction with the method but the satisfaction of past implant users was lower. Despite high contraceptive use in these populations, adverse and inaccurate beliefs about the major methods persist, particularly in Kenya. This study provides useful guidance for counselling and informational campaigns. The generally negative views of past users imply that programmes may need not only to improve individual counselling but also strengthen community information campaign to change the overall climate of opinion which may have been influenced by dissatisfaction among past users.

\section{Background}

Over the past half century, an extensive literature has been accumulated on women's attitudes and beliefs concerning contraception in general and specific methods. The extensive evidence for low- and middle-income countries (LMICs) falls into four main categories. The most common category comprises studies that examine attitudes towards and beliefs about contraception in general, with little or no distinction between specific methods [1-6]. The emphasis in many papers is on negative perceptions, often labelled as myths and misinformation. Commonly reported themes include the belief that use of modern methods will cause long term infertility, serious health damage, such as cancer and foetal abnormalities. In some studies, respondents associated contraception with promiscuity [2].

The second category concerns specific methods. Owing to the HIV pandemic, a huge literature on beliefs about condoms has been generated, much of which has been summarised by Maticka-Tyndale [7]. A review of perspectives on intra-uterine devices
(IUDs) identified 14 studies from Africa, Asia and Latin America [8]. Positive features of this method included its high effectiveness and long-acting nature while commonly expressed concerns were health risks including cancer, ectopic pregnancy, infertility and harm to the husband during intercourse. A study in Kenya found that postpartum women preferred implants over IUDs because of less pain, less infringement of modesty and preference for a superficial insertion in the upper arm than in the uterus [9]. The literature on hormonal methods shows the dominant concerns to be side effects such as nausea, dizziness and weight change, menstrual disruption and infertility [10-12]. In both Mali and Kenya, many women believed that oral contraceptives accumulate inside the body, causing infertility or a variety of diseases $[13,14]$.

The most influential, though indirect, body of evidence on views about contraceptive methods is based on selfreported reasons for non-use or discontinued use of contraception. The dominant source of data is the Demographic and Health Surveys (DHSs). The most recent analysis of reasons for non-use among married women not wishing to get pregnant found that, in most of the 52 countries studied, $20-33 \%$ cited side effects or health concerns. In 21 countries, this category of reason was the most common [15]. Moreover, in many countries, the majority of women giving this reason for contraceptive avoidance had previously used a modern method. Thus fear of side effects (and perhaps concerns about health) is partly based on personal experience and partly on hearsay evidence from friends or from media [16].

Table 1 Selected Background of Respondents

\begin{tabular}{lccc}
\hline Characteristics & Matlab & Nairobi & Homa Bay \\
\hline Educational attainment (\%) & 30.4 & 60.4 & 77.5 \\
$\quad$ Primary or less & 69.6 & 39.6 & 22.5 \\
Secondary or higher & & & \\
Current FP method use (\%) (1) & 40.7 & 24.6 & 35.5 \\
No use & 25.4 & 8.4 & 2.7 \\
Pills & 17.7 & 32.4 & 26.8 \\
Injectables & 2.2 & 19.8 & 17.9 \\
Implants & 5.5 & 1.7 & 8.1 \\
Condoms & 8.5 & 13.2 & 8.9 \\
Other & 44.8 & 27.0 & 29.2 \\
Women want no more children (\%) & 29.3 & 29.1 & 27.9 \\
Mean age of women & 1.9 & 2.3 & 3.4 \\
Mean number of living children & 2605 & 2812 & 2424 \\
Total Number of Respondents & & & \\
\hline
\end{tabular}

(1) If more than one method is used, only the most effective method is included in this table 
Table 2 Percentage of women with specific opinions, amongst those who have heard of methods (Matlab)

\begin{tabular}{|c|c|c|c|c|c|c|}
\hline Attributes & Pills & Injectables & Implants & IUD & Condoms & Female sterilisation \\
\hline \multicolumn{7}{|l|}{ Access } \\
\hline Easy & 97.2 & 90.4 & 66.1 & 69.5 & 87.1 & 71.5 \\
\hline Hard & 2.2 & 8.0 & 24.9 & 24.1 & 9.6 & 23.9 \\
\hline Don't know/unsure & 0.6 & 1.6 & 9.0 & 6.4 & 3.3 & 4.6 \\
\hline \multicolumn{7}{|l|}{ Effectiveness } \\
\hline Yes & 99.3 & 98.6 & 97.0 & 97.3 & 88.0 & 97.6 \\
\hline No & 0.5 & 1.0 & 0.5 & 0.5 & 8.3 & 0.8 \\
\hline Don't know & 0.2 & 0.4 & 2.5 & 2.2 & 3.7 & 1.6 \\
\hline \multicolumn{7}{|l|}{ Cause health problems } \\
\hline Yes, serious & 3.0 & 7.3 & 8.3 & 10.3 & 3.5 & 6.7 \\
\hline Yes, not serious & 20.5 & 33.0 & 15.3 & 15.1 & 3.0 & 8.6 \\
\hline No & 69.1 & 40.2 & 11.1 & 8.0 & 58.6 & 27.3 \\
\hline Don't know & 7.4 & 19.5 & 65.3 & 66.6 & 34.9 & 57.4 \\
\hline \multicolumn{7}{|l|}{ Interfere with menstruation } \\
\hline Yes & 7.6 & 56.8 & 15.7 & 16.5 & - & 4.3 \\
\hline No & 84.4 & 21.6 & 12.9 & 12.0 & - & 33.5 \\
\hline Don't know & 8.0 & 21.6 & 71.4 & 71.5 & - & 62.3 \\
\hline \multicolumn{7}{|l|}{ Cause unpleasant side effect } \\
\hline Yes & 26.2 & 37.8 & 18.7 & 21.5 & 7.9 & 7.7 \\
\hline No & 66.1 & 41.7 & 12.2 & 9.0 & 54.1 & 30.8 \\
\hline Don't know & 7.7 & 20.5 & 69.1 & 69.5 & 38.0 & 61.5 \\
\hline \multicolumn{7}{|c|}{ Unsafe to use for a long time } \\
\hline Yes, should take a break & 21.2 & 23.4 & 20.4 & 21.2 & 23.4 & - \\
\hline No, safe for long time & 74.3 & 67.1 & 52.7 & 53.7 & 53.7 & - \\
\hline Don't know & 4.5 & 9.5 & 26.9 & 25.1 & 22.9 & - \\
\hline \multicolumn{7}{|l|}{ Cause infertility } \\
\hline Yes, perhaps & 8.8 & 6.5 & 4.1 & 4.1 & - & - \\
\hline No & 85.2 & 84.8 & 74.8 & 76.2 & - & - \\
\hline Don't know & 6.0 & 8.7 & 21.1 & 19.7 & - & - \\
\hline \multicolumn{7}{|c|}{ FP use among friend, relatives } \\
\hline Most & 25.0 & 17.0 & 0.7 & 0.9 & 1.2 & 0.8 \\
\hline About half & 11.8 & 14.9 & 1.3 & 1.3 & 0.3 & 0.7 \\
\hline Few & 54.2 & 52.2 & 41.2 & 36.1 & 31.1 & 52.3 \\
\hline None & 4.2 & 8.2 & 28.1 & 31.8 & 14.5 & 21.1 \\
\hline Don't know & 4.8 & 7.7 & 28.6 & 29.9 & 52.9 & 25.1 \\
\hline \multicolumn{7}{|c|}{ Experiences of friend, relatives (1) } \\
\hline Satisfactory & 95.6 & 89.5 & 77.2 & 75.5 & 82.4 & 87.5 \\
\hline Unsatisfactory & 2.2 & 5.6 & 8.6 & 10.2 & 3.2 & 2.0 \\
\hline Mixed/Don't know & 2.2 & 4.8 & 14.2 & 14.3 & 14.4 & 10.5 \\
\hline \multicolumn{7}{|l|}{ Husband's approval } \\
\hline Approve & 89.4 & 71.2 & 19.9 & 22.0 & 37.5 & 14.2 \\
\hline Disapprove & 7.5 & 22.6 & 64.2 & 64.4 & 52.7 & 70.8 \\
\hline Don't know & 3.1 & 6.2 & 15.9 & 13.6 & 9.8 & 15.0 \\
\hline
\end{tabular}


Table 2 Percentage of women with specific opinions, amongst those who have heard of methods (Matlab) (Continued)

\begin{tabular}{lcccccc}
\hline Attributes & Pills & Injectables & Implants & IUD & Condoms & Female sterilisation \\
\hline Mean net positive score (2) & 61.9 & 36.2 & 24.5 & 23.6 & 45.8 & 31.8 \\
Mean \% of don't know (3) & 4.9 & 11.2 & 36.7 & 36.4 & 26.0 & 35.4 \\
TOTAL(N) & 2600 & 2583 & 2253 & 1917 & 2572 & 2544 \\
\hline
\end{tabular}

(1) Amongst those knowing some friends were using the methods

(2) Mean percent difference between percentages of women who gave positive and negative responses among the above attributes except husband's approval (3) Mean percent of women who said "don't know" to the above attributes except experiences of a method in social network and husband's approval

Reasons for discontinued use is more useful than reasons for non-use in distinguishing method-specific concerns. For oral contraceptives, injectables and IUDs, side effects or health concerns are the most common reason for stopping use. For condoms, objections from the husband or desire for a more effective method are the key reasons while for withdrawal and periodic abstinence accidental pregnancy dominates [17]. One limitation of this type of evidence is lack of comparable data for continuing users who perhaps are equally concerned about side effects or health risks as discontinued users but persist with use because of stronger motivation to avoid pregnancy or for some other reason.

The final main type of studies addresses the characteristics of contraceptive technology that women judge to be important. The single largest study of this type involved focus group discussions with 576 women in seven countries, six of which were LMICs [18]. Widespread agreement was found on the key importance of effectiveness and reversibility. Opinions varied by site on the desirability of a quick return to fertility after stopping the method and of the possibility of clandestine use. Most women found amenorrhea as a result of hormonal method use to be disturbing and similar results were found in Ghana and Nigeria [19, 20]. In a systematic review of contraceptive attributes that women take into account when choosing a method drawing on studies in USA and Europe as well as LMICs, ease of use, frequency of use, return to fertility, and side effects and health concerns were the most commonly mentioned [21].

Conspicuously and surprisingly lacking from the evidence-base for LMICs is detailed, quantitative documentation of the beliefs of women concerning all major methods of contraception. Our study addresses the omission by presenting descriptive survey data on method-specific beliefs in three populations. The data presented here form part of a wider prospective cohort study whose aims are to advance the understanding of reasons for unmet need for contraception and measurement of fertility preferences. The detailed rationale and study protocol may be found elsewhere [22]. In brief, its conceptual underpinnings posit that adverse methodspecific beliefs constitute one cause of unmet need and unintended pregnancy, alongside four other factors (generic hostility to contraception, partner-related factors, weak or inconsistent fertility preferences and low perceived risk of pregnancy). The prospective design of the study will permit assessment of the relative power of these factors to predict method-specific adoption, continuation and pregnancy-incidence. Here, however, we present data from round one with the aim of documenting method-specific beliefs and of comparing the beliefs concerning oral contraceptives, injectables and implants of current, past and never users.

\section{Methods}

The survey was conducted in the icddr,b service area and the government service area of the Matlab Health and Demographic Surveillance System (HDSS), Bangladesh, the Nairobi Urban Health and Demographic Surveillance System (NUHDSS) in two slums in Nairobi, Kenya, and Homa Bay County in rural Western Kenya. Details of the three study population have been published [22], but, in summary, contraception has been well established in Matlab for decades and the total fertility rate (TFR) is 2.7 [23]. The population is predominantly Muslim. In Nairobi slums, the TFR is 3.5 and HIV prevalence is $8 \%$ in the adult population $[24,25]$. In the two slums covered by the NUHDSS, the population is ethnically diverse, the majority belong to a Christian faith and mobility is high. Homa Bay's population is predominantly rural, Christian and of Luo ethnicity. It has a high TFR of 5.2, high unmet need for contraception and a severe HIV epidemic with an infection level in the adult population of $26 \%$ [26]. All married or cohabiting women aged between 15 and 39 years residing in the three sites were eligible for the study. We set a target sample size for each site of 2600 . The sample size was determined to detect a $30 \%$ difference in reproductive outcomes (pregnancy, use and non-use of contraceptives) at 95\% confidence level and $80 \%$ power with an assumption of $10 \%$ nonresponse rate [27].

Data collection was carried out between August and December 2016. Respondents were randomly sampled from eligible female residents from the HDSS 
Table 3 Percentage of women with specific opinions by use status (Matlab)

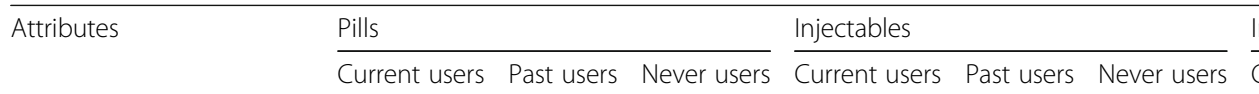
Implants

Access

Easy

Hard

Don't know/unsure

1.4

0.0

98.3

92.4

1.5

5.0

0.2

2.6

99.8

$99.4 \quad 98.5$

Yes

No

Don't know

0.2

0.6

0.6

0.0

0.0

0.9

0.9

38

Yes, serious

Yes, not serious

No

10.6

88.5

0.0

23.6

3.3

72.4

24.7

Don't know

0.2

36.6

35.4

Interfere with menstruation

Yes

No

Don't know

Cause unpleasant side effect

Yes

No

Don't know

Unsafe to use for a long time

No, safe for long time

Don't know

$\begin{array}{lll}6.0 & 9.0 & 5.8\end{array}$

93.8

90.6

56.6

0.2

0.4

37.6

$\begin{array}{lll}14.1 & 31.9 & 26.5\end{array}$

85.8

67.7

37.9

0.2

0.4

36.6

$\begin{array}{lll}18.9 & 24.7 & 14.8\end{array}$

79.8

73.4

69.9

1.3

1.9

15.2

Cause infertility

Yes, perhaps

No

6.5

10.3

90.9

85.9

7.6

76.6

3.8

15.8

FP use among friends, relatives

Most
About half
Few
None
Don't know

Experiences of friends, relatives (1)

Satisfactory
Unsatisfactory
Mixed/Don't know

Husband's approval

Approve

$$
10.5
$$$$
18.0
$$$$
48.8
$$$$
56.1
$$$$
11.3
$$

$95.3 \quad 92.4$

$94.9 \quad 63.8$

$\begin{array}{ll}4.6 & 22.7\end{array}$

1.2

0.0

\begin{abstract}
0.5
\end{abstract}
13.5

$\begin{array}{rr}98.5 & 95.5 \\ 1.5 & 4.2 \\ 0.0 & 0.3\end{array}$

95.5

84.0

84.0
13.0

4.2

13.0

3.0

$\begin{array}{rr}98.9 & 99.1 \\ 1.1 & 0.8 \\ 0.0 & 0.1\end{array}$

98.1
1.1
0.8

2.2

11.0

6.7

22.6

43.3

29.5

75.3

45.5

23.6

0.2

40.2

$\begin{array}{ll}67.9 & 72.2\end{array}$

41.8

14.0

31.0

27.5

0.3

44.2

26.3

52.3

47.3

31.8

26.0

42.2

0.4

0.4

24.5

27.0

20.5

60.9

74.4
1.1

72.1

18.6

$\begin{array}{ll}6.1 & 7.1\end{array}$

89.9

6.2

78.6

2.1

3.0

15.2

27.8

20.3

10.7

18.0

14.7

13.8

52.3

47.9

54.3

6.2

11.6

11.6

3.3

4.5

95.8
2.6
1.6

88.8

9.7

87.3

3.7

1.5

9.0

$97.6 \quad 88.9$

88.9

2.4

10.6

48.9
38.6
12.5

0.5

12.5

Current users Past users Never users

$\begin{array}{rrr}96.5 & 87.5 & 64.7 \\ 1.8 & 12.5 & 25.8 \\ 1.7 & 0.0 & 9.5\end{array}$

9.5

$\begin{array}{rrr}100.0 & 96.4 & 96.9 \\ 0.0 & 3.6 & 0.5 \\ 0.0 & 0.0 & 2.6\end{array}$


Table 3 Percentage of women with specific opinions by use status (Matlab) (Continued)

\begin{tabular}{|c|c|c|c|c|c|c|c|c|c|}
\hline \multirow[t]{2}{*}{ Attributes } & \multicolumn{3}{|l|}{ Pills } & \multicolumn{3}{|l|}{ Injectables } & \multicolumn{3}{|l|}{ Implants } \\
\hline & Current users & Past users & Never users & Current users & Past users & Never users & Current users & Past users & Never users \\
\hline \multicolumn{10}{|l|}{ Satisfied with use } \\
\hline Satisfied & 92.2 & 69.7 & - & 91.3 & 51.1 & - & 87.7 & 39.3 & - \\
\hline Unsatisfied & 4.8 & 27.7 & - & 8.0 & 47.2 & - & 10.5 & 51.8 & - \\
\hline Mixed/Neither & 3.0 & 2.6 & - & 0.7 & 1.7 & - & 1.8 & 8.9 & - \\
\hline Mean net positive score (2) & 74.8 & 60.9 & 48.8 & 53.3 & 34.7 & 31.0 & 45.8 & 19.2 & 24.0 \\
\hline Mean \% of don't know (3) & 0.8 & 1.4 & 19.2 & 1.0 & 1.2 & 22.0 & 3.9 & 5.1 & 38.4 \\
\hline TOTAL(N) & 662 & 1399 & 539 & 461 & 877 & 1245 & 57 & 56 & 2140 \\
\hline
\end{tabular}

(1) Amongst those knowing some friends were using the methods

(2) Mean percent difference between percentages of women who gave positive and negative responses among the above attributes except husband's approval (3) Mean percent of women who said "don't know" to the above attributes except experiences of a method in social network and husband's approval

Note: Chi-square test was conducted to assess associations between each of the above attributes and use status. The $p$-values were all 0.01 or smaller except the perceptions on effectiveness of injectables $(p=0.067)$

databases in the Matlab and Nairobi sites. In Homa Bay two-stage cluster sampling was used. A total of 34,308 women were identified as being married and aged between 15 and 39 years in the Matlab HDSS database. Out of these, 3109 were randomly selected and 2605 women completed the interviews. The Nairobi HDSS database identified a total of 5905 married or cohabiting women who were eligible for inclusion. Out of these, 3093 women were randomly sampled and interviews were completed with 2812 of the eligible women.

In Homa-Bay, we randomly selected 12 sub-locations (the smallest administrative unit in Kenya) in each three purposely identified sub-counties in Homa Bay County. All households with currently married or co-habiting women aged 15-49 years in the selected sub-locations were identified with the help of the local administration. Subsequently, the sampling frame was generated by listing all individuals in these households. In the second stage, 3118 were randomly sampled out of 5424 eligible women. A total of 2424 women completed the interviews.

All respondents provided written consents after having been informed about the objectives, procedures, benefits and risks of the study using an information sheet and informed consent form. All married and co-habiting adolescents aged 15-17 years were considered emancipated minors for whom parental permission is not required.

The questionnaire was developed through literature review and consultation with experts. We reviewed existing literature and more than 30 questionnaires on fertility preferences and reasons for non-use of family planning fielded in high-, middle- and low-income countries including instruments from the DHS, the Determinants of Unintended Pregnancy Risk study in New Orleans; the US- based National Survey of Family
Growth (NSFG); and the Fog Zone study by the Guttmacher Institute. A questionnaire was developed and reviewed through consultation with dozens of experts in the field. The questionnaire was further refined after pre-testing.

Structured interviews, lasting on average for 45-60 $\mathrm{min}$, were conducted using the local languages following a 7 to 10-day training. Very similar questionnaires were used in all three sites covering the following topics: background, reproduction, contraceptive knowledge and use, beliefs and attitudes towards contraception in general and specific methods and fertility preferences of the women. Two summary measures of method-specific beliefs were generated. A net positive score is the mean percent difference between positive and negative responses across nine women's attributes, ignoring "don't know" and perceived husband's approval. Positive responses refer to perceptions that a method is easy to obtain and to use, very effective in preventing pregnancy and safe to use for a long time without a break, does not cause health problems, unpleasant side effects, menstrual disruption or infertility, and that half or more of friends, relatives, neighbours (i.e. social network) had used the method and their experiences were satisfactory. A familiarity measure which is simply the mean percent responding “don't know" across eight attributes excluding experiences of method use among women's social network and perceived husband's approval. In addition, past and current users of a method were asked whether they were satisfied or dissatisfied with use.

Descriptive analysis and chi-square tests were carried out to assess differences in beliefs and attitudes among current, past and never users of pills, injectables and implants. Clustering was taken into account for the statistical analyses when analysing the data from Homa-Bay. We used STATA SE version 15.0 for the data analysis. 
Table 4 Percentage of women with specific opinions, amongst those who have heard of methods (Nairobi)

\begin{tabular}{|c|c|c|c|c|c|c|}
\hline Attributes & Pills & Injectables & Implants & IUD & Condoms & Female sterilisation \\
\hline \multicolumn{7}{|l|}{ Access } \\
\hline Easy & 92.3 & 96.7 & 89.7 & 70.0 & 88.3 & 41.8 \\
\hline Hard & 7.4 & 3.1 & 10.0 & 28.7 & 11.0 & 56.7 \\
\hline Don't know/unsure & 0.4 & 0.2 & 0.3 & 1.3 & 0.7 & 1.4 \\
\hline \multicolumn{7}{|l|}{ Effectiveness } \\
\hline Yes & 69.8 & 89.1 & 89.2 & 70.0 & 61.1 & 68.4 \\
\hline No & 29.9 & 10.8 & 10.5 & 28.1 & 38.1 & 31.1 \\
\hline Don't know & 0.3 & 0.1 & 0.3 & 1.8 & 0.8 & 0.5 \\
\hline \multicolumn{7}{|l|}{ Cause health problems } \\
\hline Yes, serious & 12.5 & 18.5 & 23.2 & 35.4 & 4.0 & 30.0 \\
\hline Yes, not serious & 28.8 & 37.1 & 36.2 & 24.6 & 11.6 & 13.5 \\
\hline No & 58.2 & 44.2 & 40.1 & 38.1 & 83.4 & 54.2 \\
\hline Don't know & 0.6 & 0.2 & 0.5 & 1.9 & 1.1 & 2.3 \\
\hline \multicolumn{7}{|l|}{ Interfere with menstruation } \\
\hline Yes & 40.5 & 78.0 & 66.5 & 48.9 & - & 30.3 \\
\hline No & 58.5 & 21.5 & 32.6 & 47.3 & - & 63.8 \\
\hline Don't know & 1.0 & 0.5 & 0.9 & 3.8 & - & 5.9 \\
\hline \multicolumn{7}{|l|}{ Cause unpleasant side effect } \\
\hline Yes & 47.2 & 59.9 & 58.7 & 58.7 & 18.0 & 40.6 \\
\hline No & 52.4 & 40.0 & 41.0 & 39.7 & 81.2 & 56.5 \\
\hline Don't know & 0.5 & 0.1 & 0.3 & 1.5 & 0.8 & 2.9 \\
\hline \multicolumn{7}{|l|}{ Unsafe to use for a long time } \\
\hline Yes, should take a break & 70.1 & 62.9 & 56.9 & 65.2 & 48.8 & - \\
\hline No, safe for long time & 29.5 & 36.7 & 42.7 & 33.3 & 49.6 & - \\
\hline Don't know & 0.4 & 0.4 & 0.4 & 1.5 & 1.6 & - \\
\hline \multicolumn{7}{|l|}{ Cause infertility } \\
\hline Yes, perhaps & 13.8 & 28.0 & 21.8 & 18.9 & - & - \\
\hline No & 85.6 & 71.6 & 77.4 & 79.2 & - & - \\
\hline Don't know & 0.5 & 0.4 & 0.8 & 1.9 & - & - \\
\hline \multicolumn{7}{|c|}{ FP use among friends, relatives } \\
\hline Most & 20.2 & 63.5 & 38.2 & 5.7 & 11.4 & 1.7 \\
\hline About half & 7.1 & 9.9 & 13.7 & 2.9 & 2.4 & 0.6 \\
\hline Few & 52.2 & 21.1 & 39.3 & 49.4 & 28.2 & 32.5 \\
\hline None & 19.7 & 4.8 & 8.3 & 40.9 & 54.8 & 64.5 \\
\hline Don't know & 0.7 & 0.7 & 0.5 & 1.0 & 3.1 & 0.7 \\
\hline \multicolumn{7}{|c|}{ Experiences of friends, relatives (1) } \\
\hline Satisfactory & 55.1 & 60.2 & 59 & 50.7 & 70.6 & 71.1 \\
\hline Unsatisfactory & 24.3 & 14.8 & 19.2 & 30.1 & 15.2 & 20.5 \\
\hline Mixed/Don't know & 20.6 & 25 & 21.9 & 19.2 & 14.3 & 8.3 \\
\hline \multicolumn{7}{|l|}{ Husband's approval } \\
\hline Approve & 63.6 & 77.4 & 62.6 & 30.6 & 29.4 & 14.0 \\
\hline Disapprove & 35.9 & 22.1 & 36.5 & 68.0 & 70.0 & 84.9 \\
\hline Don't know & 0.5 & 0.5 & 0.8 & 1.4 & 0.6 & 1.1 \\
\hline
\end{tabular}


Table 4 Percentage of women with specific opinions, amongst those who have heard of methods (Nairobi) (Continued)

\begin{tabular}{lcccccc}
\hline Attributes & Pills & Injectables & Implants & IUD & Condoms & Female sterilisation \\
\hline Mean net positive score (2) & 20.3 & 21.6 & 19.2 & 0.9 & 31.2 & 5.5 \\
Mean \% of don't know (3) & 0.5 & 0.3 & 0.5 & 1.9 & 1.4 & 2.3 \\
TOTAL (N) & 2787 & 2808 & 2789 & 2664 & 2792 & 2423 \\
\hline
\end{tabular}

(1) Amongst those knowing some friends were using the methods

(2) Mean percent difference between percentages of women who gave positive and negative responses among the above attributes except husband's approval

(3) Mean percent of women who said 'don't know' to the above attributes except experiences of a method in social network and husband's approval

Ethical approvals for this study were obtained from the Institutional Review Boards of the countries and three participating institutions.

\section{Results}

The number of women successfully interviewed was 2424 in Homa Bay, 2605 in Matlab, and 2812 in Nairobi (Additional file 1: Table S1). The average ages of women in the three sites were closely similar, 28 or 29 years (Table 1). About $70 \%$ in Matlab had secondary or higher schooling, compared with $40 \%$ in Nairobi and $23 \%$ in Homa Bay. The mean number of surviving children was lowest in Matlab, highest in Homa Bay and intermediate in Nairobi. Women in Matlab were much more likely to express a desire to stop childbearing than those in the Kenyan sites. In Nairobi, $75 \%$ were currently using a method of contraception, with injectables followed by implants, as the dominant methods. In Homa Bay, the level of current use was $65 \%$, with a method-mix similar to that in Nairobi. Current use was lowest in Matlab (59\%), where oral contraception pills and injectables were the favoured methods. But this unexpected result, in view of the far lower fertility rate in Matlab, may largely reflect the fact that $34 \%$ of husbands had been away for three months or longer preceding the date of interview, mainly as migrant workers, thus reducing the need for pregnancy-protection.

\section{Generic attitudes}

Though the focus of this paper is on method-specific beliefs, we start by presenting information on attitudes towards contraceptive use in general. In all three sites, over $90 \%$ of women reported that they supported family planning, but $25 \%$ in Homa Bay and $12 \%$ in Nairobi perceived their husbands to be opposed (Additional file 1: Table S2). Use of contraception by women's social network of friends, neighbours, and relatives was thought to be common and their attitudes were favourable in all three sites. Conversely, only around half in Matlab (51\%) and Homa Bay (47\%) and three-fourths (76\%) in Nairobi perceived that their religion supports family planning.

Large majorities considered the following features of methods to be very important: effectiveness, no health risk, lack of unpleasant side effects, no effect on menstruation, and ease of access and use (Additional file 1: Table S3). The amenability of a method for clandestine use and use for a long time without the need for re-supply were endorsed as very important by smaller majorities.

\section{Method-specific beliefs and opinions: Matlab}

A total of ten opinions and beliefs was ascertained for all women who have ever heard of each of six modern methods (Tables 2, 3, 4, 5, 6 and 7) and two traditional methods (Additional file 1: Table S4). Because of the wide array of information, the discussion here will be highly selective.

In Matlab, implants, IUDs and female sterilisation were rarely used and unfamiliarity was reflected in the high proportions of respondents who said "don't know" on attributes of these methods. Thus over half of women did not know whether these methods might cause health problems, unpleasant side effects or menstrual disruption. However, nearly all women acknowledged these three methods to be effective and two-thirds or more thought access would be easy. Among those knowing social network members who had used these methods, over three-quarters deemed their experience to be satisfactory. Yet a majority considered that their husband would disapprove of using these methods.

Oral contraceptives followed by injectables dominate the method-mix. Pills attracted more favourable opinions than injectables. For instance, $40 \%$ and 38\% thought injectables might cause health problems and unpleasant side effects, respectively, compared with $24 \%$ and $26 \%$ for pills. Nearly one-quarter thought that their husbands would disapprove of their use of injectables compared with $8 \%$ for pills. The two methods were rated similarly on other dimensions. Both were regarded as easy to obtain and effective. The experience of their social network with use of either method was judged to be satisfactory by over $90 \%$. Very few thought that either method might cause infertility and almost equal proportions considered long term use to be safe.

We compared the views of current, past and never users of pills, injectables and implants (Table 3). The largest consistent difference between current and past users across all three methods was the view that the method 
Table 5 Percentage of women with specific opinions by use status (Nairobi)

\begin{tabular}{|c|c|c|c|c|c|c|c|c|c|}
\hline \multirow[t]{2}{*}{ Attributes } & \multicolumn{3}{|l|}{ Pills } & \multicolumn{3}{|l|}{ Injectables } & \multicolumn{3}{|l|}{ Implants } \\
\hline & Current users & Past users & Never users & Current users & Past users & Never users & Current users & Past users & Never user \\
\hline \multicolumn{10}{|l|}{ Access } \\
\hline Easy & 98.3 & 94.0 & 90.6 & 99.1 & 96.9 & 93.0 & 96.7 & 92.4 & 87.1 \\
\hline Hard & 1.7 & 6.0 & 8.8 & 0.9 & 3.0 & 6.3 & 3.3 & 7.6 & 12.5 \\
\hline Don't know/unsure & 0.0 & 0.0 & 0.6 & 0.0 & 0.1 & 0.7 & 0.0 & 0.0 & 0.4 \\
\hline
\end{tabular}

Effectiveness

\begin{tabular}{|c|c|c|c|c|c|c|c|c|}
\hline Yes & 93.6 & 70.9 & 65.9 & 97.7 & 86.0 & 83.4 & 98.2 & 89.0 \\
\hline No & 6.4 & 29.0 & 33.7 & 2.3 & 14.0 & 16.2 & 1.8 & 11.0 \\
\hline Don't know & 0.0 & 0.1 & 0.4 & 0.0 & 0.0 & 0.4 & 0.0 & 0.0 \\
\hline
\end{tabular}

Cause health problems

Yes, serious
Yes, not serious
No
Don't know

5.1

18.4

$14.2 \quad 12.6$

$10.6 \quad 23.0$

$$
21.1
$$

$33.4 \quad 38.5$

39.4

32.7

$\begin{array}{lll}31.9 & 35.9 & 37.6\end{array}$

$\begin{array}{lll}0.0 & 0.2 & 0.8\end{array}$

0.1

0.0

0.6

58.5

28.4

37.2

Interfere with menstruation

Yes
No
Don't know

Cause unpleasant side effect

Yes
No
Don't know

$\begin{array}{rrrrrrrrr}25.2 & 40.7 & 42.5 & 73.0 & 82.3 & 77.1 & 59.6 & 75.1 & 66.7 \\ 74.8 & 59.0 & 55.9 & 27.0 & 17.7 & 21.0 & 40.4 & 24.9 & 31.9 \\ 0.0 & 0.2 & 1.6 & 0.0 & 0.0 & 1.9 & 0.0 & 0.0 & 1.4\end{array}$

Unsafe to use for a long time

Yes, should take a break
No, safe for long use
Don't know

$\begin{array}{ll}30.3 & 51.4 \\ 69.7 & 48.6\end{array}$

51.4

Cause infertility

Yes, perhaps
No
Don't know

0.0

51.4
48.6

$\begin{array}{ll}47.3 & 50.6 \\ 51.9 & 49.4\end{array}$

$\begin{array}{ll}65.8 & 61.7 \\ 34.2 & 37.9\end{array}$

$\begin{array}{rrr}44.8 & 70.9 & 60.1 \\ 55.2 & 28.9 & 39.5 \\ 0.0 & 0.2 & 0.4\end{array}$

$\begin{array}{rrrrrrrrr}46.2 & 69.2 & 74.0 & 49.0 & 70.0 & 69.0 & 37.9 & 61.6 & 61.6 \\ 53.8 & 30.8 & 25.4 & 50.9 & 29.9 & 29.8 & 61.9 & 38.4 & 37.9 \\ 0.0 & 0.0 & 0.7 & 0.1 & 0.2 & 1.2 & 0.2 & 0.0 & 0.5\end{array}$

FP use among friends, relatives

Most
About half
Few
None
Don't know

$\begin{array}{rr}9.8 & 13.1 \\ 89.3 & 86.8\end{array}$

13.1

\section{7}

26.1

84.6

73.6

30.0

$$
26.9
$$

72.1

$\begin{array}{rrr}16.0 & 22.7 & 23.4 \\ 83.4 & 77.0 & 75.7 \\ 0.5 & 0.2 & 0.9\end{array}$

$\begin{array}{rrr}34.2 & 26.1 & 15.3 \\ 10.7 & 7.5 & 6.5 \\ 45.3 & 50.6 & 54.0 \\ 9.8 & 15.2 & 23.5 \\ 0.0 & 0.6 & 0.8\end{array}$

Experiences of friends, relatives (1)

$\begin{array}{lr}\text { Satisfactory } & 83.4 \\ \text { Unsatisfactory } & 5.2 \\ \text { Mixed/Don't know } & 11.4 \\ \text { Husband's approval } & \end{array}$

$(1)$
83.4
5.2
11.4

$\begin{array}{ll}52 & 52.2 \\ 27.9 & 25.3 \\ 20.1 & 22.4\end{array}$

0.3

0.2

1.0

$\begin{array}{rrr}72.6 & 63.0 & 52.1 \\ 9.2 & 10.0 & 10.7 \\ 15.2 & 22.3 & 26.9 \\ 2.5 & 4.2 & 9.0 \\ 0.4 & 0.5 & 1.3\end{array}$

$\begin{array}{rrr}56.3 & 46.9 & 30.8 \\ 14.9 & 14.7 & 13.1 \\ 25.9 & 33.0 & 44.7 \\ 2.7 & 4.6 & 10.8 \\ 0.2 & 0.7 & 0.6\end{array}$

Approve

Disapprove

$\begin{array}{lll}92.3 & 71.8 & 55.3 \\ 7.69 & 28.19 & 43.82\end{array}$

0.0

0.0

43.82

$\begin{array}{rll}74.9 & 52.9 & 52.7 \\ 4.6 & 19.3 & 20.9 \\ 20.4 & 27.8 & 26.4\end{array}$

$\begin{array}{rll}75.2 & 48.8 & 56 \\ 6.6 & 25.1 & 21.9 \\ 18.2 & 26.1 & 22.1\end{array}$

Don't know

0.0

0.8

$\begin{array}{rrr}91.5 & 77.5 & 58.4 \\ 8.4 & 22.4 & 39.8 \\ 0.1 & 0.1 & 1.8\end{array}$

90.0
9.8
0.2

68.5
31.5
0.0

53.1 45.7 
Table 5 Percentage of women with specific opinions by use status (Nairobi) (Continued)

\begin{tabular}{|c|c|c|c|c|c|c|c|c|c|}
\hline \multirow[t]{2}{*}{ Attributes } & \multicolumn{3}{|l|}{ Pills } & \multicolumn{3}{|l|}{ Injectables } & \multicolumn{3}{|l|}{ Implants } \\
\hline & Current users & Past users & Never users & Current users & Past users & Never users & Current users & Past users & Never users \\
\hline \multicolumn{10}{|l|}{ Satisfied with use } \\
\hline Satisfied & 90.2 & 41.3 & - & 87.7 & 44.9 & - & 86.5 & 32.3 & - \\
\hline Unsatisfied & 8.5 & 55.8 & - & 10.5 & 53.2 & - & 10.7 & 64.8 & - \\
\hline Mixed/Neither & 1.3 & 2.3 & - & 1.3 & 1.3 & - & 2.0 & 2.0 & - \\
\hline Missing & 0.0 & 0.6 & - & 0.6 & 0.6 & - & 0.7 & 1.0 & - \\
\hline Mean net positive score (2) & 53.4 & 19.8 & 15.8 & 38.0 & 14.1 & 13.0 & 44.5 & 11.8 & 13.2 \\
\hline Mean \% of don't know (3) & 0.1 & 0.2 & 0.8 & 0.1 & 0.1 & 1.0 & 0.1 & 0.2 & 0.7 \\
\hline TOTAL(N) & 234 & 869 & 1684 & 909 & 1218 & 681 & 549 & 409 & 1831 \\
\hline
\end{tabular}

(1) Amongst those knowing some friends were using the methods

(2) Mean percent difference between percentages of women who gave positive and negative responses among the above attributes except husband's approval

(3) Mean percent of women who said "don't know" to the above attributes except experiences of a method in social network and husband's approval

Note: Chi-square test was conducted to assess associations between each of the above attributes and use status. The p-values were all 0.01 or smaller except the perceptions on risk of infertility of pills $(p=0.061)$ and injectables $(p=0.015)$

caused unpleasant side effects, though appreciable minorities (from $14 \%$ for the pill to $30 \%$ for the implant) of current users acknowledged side effects. Notably, $29 \%$ of past implant users thought that the method caused serious health problems. Furthermore, past implant users were more likely to rate their experience as unsatisfactory than past injectable or pill users.

\section{Method-specific beliefs and opinions: Nairobi}

As indicated by the mean net positive scores, beliefs about methods were less favourable in Nairobi than in Matlab and the proportions giving "don't know" responses were much lower. With the exception of sterilisation, large majorities considered methods easy to obtain (Table 4). Injectables and implants were judged to be effective by $90 \%$. However, in a clear departure from objective evidence, this level falls to about $70 \%$ for IUDs and sterilisation. The view that a method might cause serious health problems was widespread (with the exception of condoms), rising from $13 \%$ for pills to $30 \%$ for sterilisation and $35 \%$ for IUDs. Similarly, about $60 \%$ associated injectables, implants, and IUDs with unpleasant side effects, as did over $40 \%$ for pills and sterilisation. Only minorities were of the view that the hormonal methods and IUDs could be safely used for a long time without taking a break. Between 14\% (pills) and 28\% (injectables) of women thought that a method might cause infertility. Despite these views, between $51 \%$ and $71 \%$ rated the experience of social network members with use of methods as satisfactory. While most women thought that their partners would approve of their use of pills, injectables and implants, perceived approval dropped to $30 \%$ for IUDs and condoms and further to $14 \%$ for sterilisation.

Analysis of opinions by use status showed sharp divides between current users and past or never users (Table 5). For instance, $11 \%$ of current injectable users (the dominant method in this site) believed that the method caused serious health problems compared with over $20 \%$ of past or never users. This difference was more pronounced for implants: $10 \%$ for current users versus $36 \%$ for past users and $25 \%$ for never users. Similarly, about three quarters of current users of injectables, pills and implants reported satisfactory experience of their social network compared with about $50 \%$ of past and never users. A clear gradient in perceived partner's approval is apparent for all three methods, with $90 \%$ approval for current users, around $70 \%$ for past users and $50-60 \%$ for never users. Nevertheless, appreciable proportions of current users held negative views about their method: $30 \%$, $51 \%$ and $45 \%$ of pill, injectable and implant users, respectively, thought that the method caused unpleasant side effects. Around $40 \%$ of current users considered their method to be unsafe for prolonged use. Despite these reservations, close to $90 \%$ of current users rated their method as satisfactory compared with $32-44 \%$ of past users.

\section{Method-specific beliefs and opinions: Homa Bay}

Condoms received a much higher mean net positive score than other methods and perceived partner's approval of this method was higher in this site with high adult HIV prevalence than in Matlab or Nairobi. The experience of social network members with use of condoms was more likely to be rated as satisfactory than other methods: $73 \%$ for condoms compared with $54-58 \%$ for the two dominant methods, injectables and implants (Table 6). Condoms were more likely to be considered as effective than pills, though less likely than injectables and implants.

With the exception of condoms, about 30\% thought that other methods caused serious health problems; between $38 \%$ (sterilisation) and $63 \%$ (injectables) 
Table 6 Percentage of women with specific opinions, amongst those who have heard of methods (Homa Bay)

\begin{tabular}{|c|c|c|c|c|c|c|}
\hline Attributes & Pills & Injectables & Implants & IUD & Condoms (4) & Female sterilisation (5) \\
\hline \multicolumn{7}{|l|}{ Access } \\
\hline Easy & 79.4 & 90.4 & 84.5 & 52.8 & 93.9 & 41.7 \\
\hline Hard & 12.5 & 7.9 & 10.5 & 25.8 & 3.6 & 40.3 \\
\hline Don't know/unsure & 8.1 & 1.6 & 5.0 & 21.4 & 2.5 & 18.0 \\
\hline \multicolumn{7}{|l|}{ Effectiveness } \\
\hline Yes & 62.6 & 91.6 & 90.3 & 66.1 & 77.5 & 82.5 \\
\hline No & 23.8 & 5.6 & 3.7 & 8.6 & 17.4 & 5.4 \\
\hline Don't know & 13.5 & 2.8 & 6.0 & 25.3 & 5.1 & 12.1 \\
\hline \multicolumn{7}{|l|}{ Cause health problems } \\
\hline Yes, serious & 37.8 & 31.2 & 28.3 & 36.0 & 11.4 & 32.7 \\
\hline Yes, not serious & 21.5 & 31.0 & 25.9 & 16.0 & 11.3 & 12.2 \\
\hline No & 23.0 & 30.1 & 30.5 & 18.7 & 70.0 & 31.5 \\
\hline Don't know & 17.7 & 7.7 & 15.4 & 29.3 & 7.3 & 23.6 \\
\hline \multicolumn{7}{|l|}{ Interfere with menstruation } \\
\hline Yes & 56.5 & 80.2 & 60.1 & 35.6 & - & - \\
\hline No & 22.1 & 14.7 & 22.5 & 25.1 & - & - \\
\hline Don't know & 21.4 & 5.2 & 17.4 & 39.2 & - & - \\
\hline \multicolumn{7}{|l|}{ Cause unpleasant side effect } \\
\hline Yes & 57.5 & 63.2 & 51.7 & 44.7 & 14.0 & 38.3 \\
\hline No & 21.6 & 28.7 & 30.1 & 20.9 & 77.6 & 36.0 \\
\hline Don't know & 20.9 & 8.2 & 18.2 & 34.4 & 8.4 & 25.7 \\
\hline \multicolumn{7}{|l|}{ Unsafe to use for a long time } \\
\hline Yes, should take a break & 66.9 & 68.5 & 60.8 & 62.5 & 37.3 & - \\
\hline No, safe for long time & 20.3 & 26.3 & 31.7 & 17.4 & 56.4 & - \\
\hline Don't know & 12.8 & 5.2 & 7.6 & 20.0 & 6.3 & - \\
\hline \multicolumn{7}{|l|}{ Cause infertility } \\
\hline Yes, perhaps & 15.6 & 17.1 & 12.7 & 16.2 & - & - \\
\hline No & 72.9 & 77.3 & 78.1 & 63.4 & - & - \\
\hline Don't know & 11.6 & 5.7 & 9.2 & 20.5 & - & - \\
\hline \multicolumn{7}{|c|}{ FP use among friends, relatives } \\
\hline Most & 13.9 & 64.6 & 49.1 & 3.9 & 30.3 & 3.3 \\
\hline About half & 7.4 & 8.3 & 8.7 & 3.5 & 7.7 & 2.7 \\
\hline Few & 49.3 & 19.0 & 31.8 & 42.4 & 26.0 & 51.3 \\
\hline None & 13.8 & 2.1 & 3.7 & 26.9 & 6.1 & 26.0 \\
\hline Don't know & 15.7 & 6.0 & 6.8 & 23.4 & 30.0 & 16.7 \\
\hline \multicolumn{7}{|c|}{ Experiences of friends, relatives (1) } \\
\hline Satisfactory & 38.0 & 54.1 & 57.7 & 39.4 & 72.9 & 59.1 \\
\hline Unsatisfactory & 28.5 & 11.2 & 13.1 & 27.2 & 10.6 & 17.3 \\
\hline Mixed/Don't know & 33.5 & 34.7 & 29.2 & 33.4 & 16.5 & 17.1 \\
\hline \multicolumn{7}{|l|}{ Husband disapprove } \\
\hline Approve & 45.5 & 64.4 & 52.2 & 25.2 & 53.3 & 18.1 \\
\hline Disapprove & 43.7 & 30.2 & 38.7 & 58.8 & 41.2 & 70.5 \\
\hline Don't know & 10.8 & 5.5 & 9.1 & 15.9 & 5.5 & 11.4 \\
\hline
\end{tabular}


Table 6 Percentage of women with specific opinions, amongst those who have heard of methods (Homa Bay) (Continued)

\begin{tabular}{lcccccc}
\hline Attributes & Pills & Injectables & Implants & IUD & Condoms (4) & Female sterilisation (5) \\
\hline Mean net positive score (2) & -2.5 & 16.6 & 20.1 & -3.4 & 49.8 & 5.6 \\
Mean \% of don't know (3) & 15.2 & 5.3 & 10.7 & 26.7 & 9.9 & 19.2 \\
TOTAL(N) & 2358 & 2405 & 2391 & 1973 & 1338 & 2080
\end{tabular}

(1) Amongst those knowing some friends were using the methods

(2) Mean percent difference between percentages of women who gave positive and negative responses among the above attributes except husband's approval

(3) Mean percent of women who said "don't know" to the above attributes except experiences of a method in social network and husband's approval

(4) 1008 responses missing owing to error in electronic data capture program

(5) The question on interference with menstruation was not asked for female sterilisation in Homa-Bay

considered that methods caused unpleasant side effects and about two-thirds judged methods to be unsafe for prolonged use without taking a break.

As in Nairobi, current users of pills, injectables and implants were much more likely to express positive views about their method than past or never users, except with regard to fears among a minority of women about infertility. However, the prevalence of adverse views even among current users was striking. Thus, $14 \%, 24 \%$ and $16 \%$ of current pill, injectable and implant users, respectively, considered that their method caused serious health problems and between $34 \%$ and $55 \%$ associated the method with unpleasant side effects. These adverse beliefs did not translate into dissatisfaction with the current method: on the contrary, between $77 \%$ and $88 \%$ judged their method to be satisfactory while only $31-45 \%$ of past users were satisfied with the use.

\section{Discussion}

In view of the principle of cognitive dissonance-the tendency to align beliefs and attitudes to behaviour-it is no surprise that most current users of a method consider it to be satisfactory and express more positive views than past or never users. In apparent contradiction to high overall satisfaction is the finding that appreciable proportions of these current users appear to be concerned about serious health effects and acknowledge that the method causes unpleasant side effects. The view that it is unsafe to use a method for a long time without taking a break is widespread among current users, particularly in the Kenyan sites. Follow-up surveys will establish the impact of these perceptions on discontinuation.

Dissatisfaction among past users, who tend to outnumber current users, may be a powerful influence on the overall climate of opinion; indeed the views of past and never users tend to be similar. The low level of overall satisfaction among past users of injectables, pills and implants in Kenyan sites, associated with health worries and side effects, is a concern, particularly with implant users of whom only about $30 \%$ in Nairobi reported satisfaction. A continuation of the steep rise in the use of implants in Kenya, therefore, could be in jeopardy. Similarly in Matlab, the results imply considerable potential resistance to long-acting reversible methods (IUDs and implants), the promotion of which is a national priority.

The study is not without limitations. Information on perceived partner's approval of specific methods is difficult to interpret. While close to $90 \%$ reported partner's support of family planning in general, perceived approval is low in Matlab for use of implants, IUDs and female sterilisation, and also low in the Kenyan sites for use of IUDs and sterilisation. Whether or not, these results reflect women's own misgivings about these methods remains unclear.

The value of this detailed information in explaining reproductive and contraceptive behaviour is uncertain and a verdict must await the results of follow-up surveys. Nevertheless, the results are of considerable interest because this study, to our knowledge, is the first to have obtained comparable quantitative information in LMICs on attitudes and beliefs on each of eight major family planning methods. Many of the findings from this study are consistent with earlier studies that have documented fears about side effects and damage to health to be widespread. The result regarding the belief that it is unsafe to use a method for a long term without taking a break is simiar to the common behaviours observed in the Philippines [28]. Other findings are new and have considerable possible implications for behaviour.

Moreover, the ability of this study to contrast the beliefs of current, past and never users of the three more prevalent methods represents a major contribution. In 2015 an expert meeting on misperceptions about contraceptives called for a revitalization of discussion on this issue. Participants identified the need for quantitative data that distinguish concerns stemming from documented side effects from those resulting from rumours or myths and the need for evidence about links between misperceptions and method choice [29]. This paper starts to address these gaps in evidence and further progress is expected when follow-up survey data become available. 
Table 7 Percentage of women with specific opinions by use status (Homa Bay)

\begin{tabular}{|c|c|c|c|c|c|c|c|c|c|}
\hline \multirow[t]{2}{*}{ Attributes } & \multicolumn{3}{|l|}{ Pills } & \multicolumn{3}{|l|}{ Injectables } & \multicolumn{3}{|l|}{ Implants } \\
\hline & Current users & Past users & Never users & Current users & Past users & Never users & Current users & Past users & Never user \\
\hline \multicolumn{10}{|l|}{ Access } \\
\hline Easy & 92.3 & 84.7 & 77.1 & 93.7 & 90.6 & 87.0 & 93.9 & 88.7 & 81.1 \\
\hline Hard & 7.7 & 12.5 & 12.7 & 6.2 & 8.7 & 8.4 & 6.2 & 8.3 & 12.1 \\
\hline Don't know/unsure & 0.0 & 2.8 & 10.3 & 0.2 & 0.7 & 4.6 & 0.0 & 3.0 & 6.9 \\
\hline
\end{tabular}

Effectiveness

$\begin{array}{lrrrrrrrrr}\text { Yes } & 86.2 & 66.8 & 60.3 & 97.1 & 92.1 & 85.2 & 98.6 & 89.9 & 88.1 \\ \text { No } & 10.8 & 28.5 & 22.8 & 2.1 & 7.0 & 6.8 & 1.1 & 5.7 & 4.0 \\ \text { Don't know } & 3.1 & 4.7 & 16.9 & 0.8 & 0.8 & 8.0 & 0.2 & 4.5 & 7.9\end{array}$

Cause health problems

Yes, serious
Yes, not serious
No
Don't know

13.9

Interfere with menstruation

Yes
No
Don't know

$40.0 \quad 59.6$

53.9

32.5

37.0

Cause unpleasant side effect

Yes
Non't know

Unsafe to use for a long time

Yes, should take a break
No, safe for long time
Don't Know

$\begin{array}{rrrrrrrrr}47.7 & 70.5 & 66.4 & 58.0 & 73.7 & 70.6 & 50.8 & 65.2 & 62.6 \\ 40.0 & 22.4 & 18.9 & 37.3 & 23.6 & 19.9 & 47.2 & 29.8 & 27.9 \\ 12.3 & 7.1 & 14.7 & 4.7 & 2.7 & 9.5 & 2.1 & 5.1 & 9.6\end{array}$

Cause infertility

Yes, perhaps
No
Don't know

$\begin{array}{rrrrrrrrr}15.4 & 15.6 & 15.6 & 15.4 & 16.8 & 19.3 & 10.7 & 13.4 & 13.1 \\ 80.0 & 77.4 & 71.1 & 80.5 & 80.0 & 69.8 & 83.4 & 81.0 & 76.1 \\ 4.6 & 6.9 & 13.4 & 4.1 & 3.2 & 11.0 & 5.9 & 5.7 & 10.8\end{array}$

FP use among friends, relatives

$\begin{array}{ll}\text { Most } & 18.5 \\ \text { About half } & 10.8 \\ \text { Few } & 50.8 \\ \text { None } & \\ \text { Don't know } & 12.3\end{array}$

Experiences of friends, relatives (1)

$\begin{array}{lrrrrrrrrr}\text { Satisfactory } & 65.4 & 39.7 & 36.2 & 69.0 & 48.2 & 47.9 & 77.6 & 49.2 & 53.6 \\ \text { Unsatisfactory } & 11.5 & 34.9 & 27.0 & 4.0 & 15.4 & 11.7 & 3.8 & 21.6 & 14.1 \\ \quad \begin{array}{l}\text { Mixed/Don't know } \\ \text { Husband's approval }\end{array} & 23.1 & 25.5 & 36.7 & 27.0 & 36.4 & 40.4 & 18.6 & 29.2 & 32.3 \\ \text { Approve } & & & & & & & & \\ \text { Disapprove } & 76.9 & 55.6 & 40.9 & 77.2 & 67.5 & 47.0 & 77.7 & 59.8 & 43.7 \\ \text { Don't know } & 20.0 & 38.4 & 46.4 & 20.7 & 29.1 & 41.1 & 20.7 & 36.0 & 44.2 \\ & 3.1 & 6.1 & 12.6 & 2.1 & 3.4 & 12.0 & 1.6 & 4.2 & 12.1\end{array}$


Table 7 Percentage of women with specific opinions by use status (Homa Bay) (Continued)

\begin{tabular}{|c|c|c|c|c|c|c|c|c|c|}
\hline \multirow[t]{2}{*}{ Attributes } & \multicolumn{3}{|l|}{ Pills } & \multicolumn{3}{|l|}{ Injectables } & \multicolumn{3}{|l|}{ Implants } \\
\hline & Current users & Past users & Never users & Current users & Past users & Never users & Current users & Past users & Never users \\
\hline \multicolumn{10}{|l|}{ Satisfied with use } \\
\hline Satisfied & 76.9 & 38.4 & - & 86.1 & 44.9 & - & 87.7 & 31.0 & - \\
\hline Unsatisfied & 16.9 & 43.6 & - & 6.3 & 38.7 & - & 7.1 & 30.1 & - \\
\hline Mixed/Neither & 3.1 & 6.3 & - & 5.1 & 9.0 & - & 5.2 & 3.3 & - \\
\hline Missing (4) & 3.1 & 11.8 & - & 2.4 & 7.3 & - & 0.0 & 35.7 & - \\
\hline Mean net positive score (2) & 31.1 & -0.3 & -4.5 & 29.7 & 12.8 & 9.6 & 42.1 & 16.6 & 14.8 \\
\hline Mean \% of don't know (3) & 6.3 & 7.5 & 18.1 & 3.0 & 2.7 & 11.5 & 3.4 & 5.8 & 13.7 \\
\hline TOTAL(N) & 65 & 576 & 1717 & 662 & 1066 & 677 & 439 & 336 & 1616 \\
\hline
\end{tabular}

(1) Amongst those knowing some friends were using the methods

(2) Mean percent difference between percentages of women who gave positive and negative responses among the above attributes except husband's approval

(3) Mean percent of women who said "don't know" to the above attributes except experiences of a method in social network and husband's approval

(4) The missing occurred due to initial technical errors in the electronic data capture

Note: Chi-square test was conducted to assess associations between each of the above attributes and use status. The p-values were all 0.002 or smaller

\section{Conclusions}

In conclusion, high levels of contraceptive use can clearly co-exist with widespread misgivings about methods, even those that are widely used. Serious concerns about damage to health, long term fertility impairment, and dangers of prolonged use without taking a break were particularly common in the Kenyan sites and these beliefs may explain the high levels of discontinuation observed in Kenya and elsewhere in Africa. This documentation of beliefs provides useful guidance for counselling and informational campaigns. The generally negative views of past users imply that programmes may need not only to improve individual counselling but also strengthen community information campaign to change the overall climate of opinion which may have been influenced by dissatisfaction among past users.

\section{Additional file}

Additional file 1: Table S1. Enrollment Overview. Table S2. General attitudes by site. Table S3. Percentage of respondents stating specific characteristics to be 'very important' by site. Table S4. Percentage of women with specific opinions (traditional methods) by site. (PDF 916 kb)

\section{Acknowledgements}

The authors thank the women who participated in this study and the teams worked at the three study sites, Matlab, Nairobi and Homa-Bay, and at icddr, b, APHRC, Population Council, Kenya. We would like to thank the members of the STEP UP Consortium Advisory Group and Senior Management Team for their invaluable feedback in the design and implementation of the study.

\section{Funding}

The Improving Measurement of Unintended Pregnancy and Unmet Need for Family Planning study was funded by the UK Department for International Development (DFID) through the Strengthening Evidence for Programming on Unintended Pregnancy (STEP UP).

\section{Availability of data and materials}

The data during the current study are not publicly available because further analyses are being conducted to answer additional questions. Any question or query may be addressed to the corresponding author and those publications will be shared when available.

\section{Authors' contributions}

KM was the principal investigator $(\mathrm{PI})$ and responsible for the overall study coordination and implementation of the study. JC, KM and JBC conceptualized the study and led development of study design, questionnaire and analysis plans. JNM, FAH and FO are the site PIs and were responsible for the implementation of the study in the respective sites. FA, $\mathrm{GO}$ and $\mathrm{MW}$ conducted the analysis and the results were reviewed by KM, FAH, JNM and JC. JC and KM prepared the first draft and tables for the manuscript, FAH, GO, JNM, JBC, FA reviewed and provided inputs for revisions. All authors read and approved the final manuscript.

\section{Ethics approvals and consent to participate}

Ethical approvals for this study were granted from the Institutional Review Boards of the London School of Hygiene and Tropical Medicine and Population Council as well as by the AMREF Ethics and Scientific Review Committee for the Nairobi site, Kenyatta National Hospital-University of Nairobi Ethics and Research Committee for the Homa-Bay site and icddr,b Institutional Review Board (Research Review Committee and Ethical Review Committee) for the Matlab site, respectively. All adolescents aged 15-17 years who were married or co-habiting with a partner were considered emancipated minors for which parental permission is not required. All study participants gave written informed consent to participate in the study.

\section{Competing interests}

The authors declare that they have no competing interests.

\section{Publisher's Note}

Springer Nature remains neutral with regard to jurisdictional claims in published maps and institutional affiliations.

\section{Author details}

${ }^{1}$ Faculty of Epidemiology and Population Health, London School of Hygiene and Tropical Medicine, Keppel Street, London WC1E 7HT, UK. ${ }^{2} \mathrm{icddr}, \mathrm{b}$, Dhaka, Bangladesh. ${ }^{3}$ Population Council, Nairobi, Kenya. ${ }^{4}$ African Population and Health Research Center, Nairobi, Kenya. ${ }^{5}$ Institute for Population Research, Ohio State University, Columbus, USA.

Received: 22 December 2017 Accepted: 24 April 2018

Published online: 08 May 2018

\section{References}

1. Kabagenyi A, Reid A, Ntozi J, Atuyambe L. Socio-cultural inhibitors to use of modern contraceptive techniques in rural Uganda: a qualitative study. Pan Afr Med J. 2016. https://doi.org/10.11604/pamj.2016.25.78.6613.

2. Ochako R, Mbondo M, Aloo S, Kaimenyi S, Thompson R, Temmerman M, Kays M. Barriers to modern contraceptive methods uptake among young women in Kenya: a qualitative study. BMC Public Health. 2015. https://doi. org/10.1186/s12889-015-1483-1. 
3. Gueye A, Speizer IS, Corroon M, Okigbo CC. Belief in family planning myths at the individual and community levels and modern contraceptive use in urban Africa. Int Perspect Sex Reprod Health. 2015. https://doi.org/10.1363/ 4119115.

4. Morse JE, Rowen TS, Steinauer J, Byamugisha J, Kakaire O. A qualitative assessment of Ugandan women's perceptions and knowledge of contraception. Int J Gynaecol Obstet. 2014. https://doi.org/10.1016/j.jjgo. 2013.07.014

5. Chipeta EK, Chimwaza W, Kalilani-Phiri L. Contraceptive knowledge, beliefs and attitudes in rural Malawi: misinformation, misbeliefs and misperceptions. Malawi Med J. 2010.

6. Mosha I, Ruben R, Kakoko D. Family planning decisions, perceptions and gender dynamics among couples in Mwanza, Tanzania: a qualitative study. BMC Public Health. 2013. https://doi.org/10.1186/1471-2458-13-523.

7. Maticka-Tyndale E. Condoms in sub-Saharan Africa. Sex Health. 2012. https://doi.org/10.1071/SH11033.

8. Daniele MAS, Cleland J, Benova L, Ali M. Provider and lay perspectives on intra-uterine contraception: a global review. Reprod Health. 2017. https:// doi.org/10.1186/s12978-017-0380-8.

9. Hubacher D, Masaba R, Manduku CK, Veena V. Uptake of the levonorgestrel intrauterine system among recent postpartum women in Kenya: factors associated with decision-making. Contraception. 2013. https://doi.org/10. 1016/j.contraception.2013.03.001.

10. Grubb GS. Women's perceptions of the safety of the pill: a survey in eight developing countries. Report of the perceptions of the pill survey group. J Biosoc Sci. 1987;19(3):313-21.

11. Williamson LM, Parkes A, Wight D, Petticrew M, Hart GJ. Limits to modern contraceptive use among young women in developing countries: a systematic review of qualitative research. Reprod Health. 2009. https://doi. org/10.1186/1742-4755-6-3.

12. Hardon A. Women's views and experiences of hormonal contraceptives: what we know and what we need to find out. Beyond acceptability: users' perspectives on contraception. London: Reproductive Health Matters; 1997. Accessed.

13. Castle S. Factors influencing young Malians' reluctance to use hormonal contraceptives. Stud Fam Plan. 2003. https://doi.org/10.1111/j.1728-4465. 2003.00186.x.

14. Rutenberg N, Watkins SC. The buzz outside the clinics: conversations and contraception in Nyanza Province, Kenya. Stud Fam Plan. 1997;28(4):290307.

15. Sedgh G, Ashford LS, Hussain R. Unmet need for contraception in developing countries: examining women's reasons for not using a method. New York: Guttmacher Institute; 2016. https://www.guttmacher.org/sites/ default/files/report_pdf/unmet-need-for-contraception-in-developingcountries-report.pdf. Accessed 4 Apr 2018.

16. Diamond-Smith N, Campbell M, Madan S. Misinformation and fear of sideeffects of family planning. Cult Health Sex. 2012; https://doi.org/10.1080/ 13691058.2012.664659.

17. Ali MM, Cleland JG, Shah $\mathrm{H}$. Causes and consequences of contraceptive discontinuation: evidence from 60 demographic and health surveys Geneva: WHO; 2012. http://apps.who.int/iris/bitstream/handle/10665/75429/ 9789241504058_eng.pdf; jsessionid= 85F4F8A8BE3BBE2AF2CAB109A0D5AE78? sequence=1. Accessed 4 Apr 2018.

18. Snow R, Garcia S, Kureshy N, Sadana R, Singh S, Becerra-Valdivia M, Lancaster S, Mofokeng M, Hoffman M, Aitken I. Attributes of contraceptive technology: women's preferences in seven countries. Beyond acceptability: users' perspectives on contraception. London: Reproductive Health Matters; 1997. Accessed.

19. Hindin MJ, McGough L, Misperceptions AR. Misinformation and myths about modern contraceptive use in Ghana. J Fam Plann Reprod Health Care. 2014. https://doi.org/10.1136/jfprhc-2012-100464.

20. Glasier AF, Smith KB, van der Spuyb Z, Ho PC, Cheng L, Dada K, Wellings K, Bairda DT. Amenorrhea associated with contraception-an international study on acceptability. Contraception. 2003. https://doi.org/10.1016/S00107824(02)00474-2.

21. Wyatt KD, Anderson RT, Creedon D, Montori VM, Bachman J, Erwin P, LeBlanc A. Women's values in contraceptive choice: a systematic review of relevant attributes included in decision aids. BMC Womens Health. 2014 https://doi.org/10.1186/1472-6874-14-28.

22. Machiyama K, Casterline JB, Mumah JN, Huda FA, Obare F, Odwe G, Kabiru $\mathrm{CW}$, Yeasmin S, Cleland J. Reasons for unmet need for family planning, with attention to the measurement of fertility preferences: protocol for a multisite cohort study. Reprod Health. 2017. https://doi.org/10.1186/s12978-0160268-z.

23. icddr, b. Health and demographic surveillance system-Matlab: registration of health and demographic events 2015. Scientific report no 135. Dhaka. Icddr, b. 2015.

24. National Aids Control Council. Kenya HIV Country Profiles. Nairobi. National Aids Control Council. 2014. Accessed.

25. African Population and Health Research Center. Population and Health Dynamics in Nairobi's Informal Settlements: Report of the Nairobi Crosssectional Slums Survey (NCSS) 2012. Nairobi. APRHC; 2014. http://aphrc.org/ wp-content/uploads/2014/08/NCSS2-FINAL-Report.pdf. Accessed 4 Apr 2018

26. Kenya Bureau of Statistics, Ministry of Health, national AIDS control council, Kenya medical research institute, National Council for population and development, ICF international. Kenya demographic and health survey 2014. Rockville: ICF International; 2015.

27. Fleiss $J$, Levin B, Paik MC. Statistical methods for rates and proportions. Third ed. Hoboken: Wiley; 2003.

28. Henry R. Contraceptive practice in Quirino Province. Philippines: Experiences of Side Effects. Calverton: University of the Philippines Population Institute, University of La Salette, Macro International; 2001. https://pdf.usaid.gov/pdf docs/PNACM416.pdf. Accessed 4 Apr 2018.

29. Wells E. Countering myths and misperceptions about contraceptives. PATH: Outlook on Reproductive Health. Seattle; 2015. https://www.path.org/ publications/files/RH_outlook_myths_mis_june_2015.pdf. Accessed 4 Apr 2018.

\section{Ready to submit your research? Choose BMC and benefit from}

- fast, convenient online submission

- thorough peer review by experienced researchers in your field

- rapid publication on acceptance

- support for research data, including large and complex data types

- gold Open Access which fosters wider collaboration and increased citations

- maximum visibility for your research: over $100 \mathrm{M}$ website views per year

At BMC, research is always in progress.

Learn more biomedcentral.com/submissions 